\title{
ФАКТОРЫ, ВЛИЯЮЩИЕ НА СНИЖЕНИЕ ГИДРОПРОВОДНОСТИ ПРИЗАБОЙНОЙ ЗОНЫ СКВАЖИНЫ
}

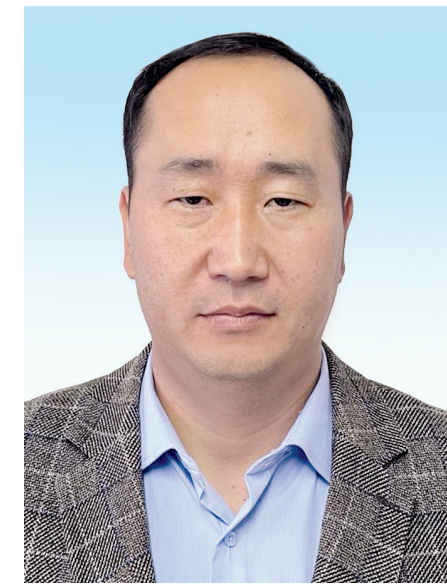

Н.С. СУЛЕЙМЕНОВ*, кандидат технических наук, зав. кафредрой «Инжиниринговые технологии и экология», https://orcid.org/0000-0002-40394900

КЫЗЫЛОРДИНСКИЙ УНИВЕРСИТЕТ ИМ. КОРКЫТ АТА, Республика Казахстан, 120014, г. Кызылорда, ул. Айтеке би, 29А

Проведены аналитические исследования влияния зоны проникновения твердых и жидких фраз промывочных растворов при вскрытии продуктивных отложений бурением на гидродинамическое совершенство призабойной зоны пласта.

В буровой практике при вскрытии продуктивных пластов бурением стремятся максимально сократить фильтрацию в пласт, регулируя параметр «водоотдача» и интенсифрицируя кольматацию пристенных участков коллектора.

В конструкциях забоя с «открытым» стволом гидродинамическое совершенство скважины в значительной степени определяется зоной загрязнения призабойной зоны пласта, т.к. при притоке в скважину эта зона создает дополнительные гидродинамические сопротивления, на преодоление которых затрачивается значительная часть пластовой энергии.

КЛЮЧЕВЫЕ СЛОВА: призабойная зона пласта, загрязнение продуктивного пласта, фильтрационная корка, зона кольматации, зона проникновения фрильтрата, проницаемость, фрильтрация, скин-фрактор.

\footnotetext{
* Адрес для переписки. E-mail: nurzhan_suleymen@mail.ru
} 


\section{ҰНҒЫМАНЫН КЕНЖАР МАНЫ АЙМАҒЫНЫН ГИДРОӨТКІЗГІШТІГІНІН ТӨМЕНДЕУІНЕ ӘСЕР ЕТЕТІН ФАКТОРЛАР}

Н.С. СүЛЕЙмЕноВ*, техника ғылымдарының кандидаты, Қорқыт Ата атындағы Қызылорда университетінің «Инжинирингтік технологиялар және экология» кафедрасының меңгерушісі, https://orcid.org/0000-0002-4039-4900

ҚОРҚЫТ АТА АТЫНДАҒЫ ҚЫЗЫЛОРДА УНИВЕРСИТЕТІ,

Қазақстан Республикасы, 120014, Қызылорда қ., Әйтеке би көшесі, 29A

Ұңғыма кенжар маңы аймағының гидродинамикалық жетілгендігіне бұрғылау арқылы өнімді қабатты ашу кезінде жуу ерітінділерінің қатты және сұйық фразаларының ену аймағының әсеріне аналитикалық зерттеулер жүргізілді .

Бұрғылау тәжірибесінде өнімді қабаттарды алғашқы ашу кезінде «су бергіштік» параметрін реттеу және қабаттың қабырғаға жақын учаскелерінің бітелуін күшейту арқылы қабатқа фрильтрацияны барынша азайтуға тырысады.

«Ашық» түпті құрылымды ұңғыманың гидродинамикалық жетілгендігі негізінен ұңғыманың түпкі қабатының ластану аймағымен анықталады, өйткені ұңғымаға сұйық келу кезінде бұл аймақ қосымша гидродинамикалық кедергілер жасайды, оны еңсеруге қабаттың айтарлықтай энергиясы жұмсалады.

ТҮЙІн СөзДЕР: қабат түп аймағы, өнімді қабаттың ластануы, фильтрациялық қабықша, кольматация аймағы, фрильтраттың ену аймағы, өткізаіштік, фрильтрация, скин- фрактор.

\section{FACTORS INFLUENCING THE REDUCTION OF WATER CONDUCTIVITY OF THE BOTTOM BOREHOLE ZONE}

N.S. SULEIMENOV, Candidate of Technical Sciences, Head of the Department of Engineering Technologies and Ecology of the Korkyt Ata Kyzylorda University, https://orcid.org/0000-00024039-4900

\section{KORKYT ATA KYZYLORDA UNIVERSITY,} 29a, Aiteke bi street, Kyzylorda, 120000, Kazakhstan

Analytical studies of the influence of the penetration zone of solid and liquid phases of washing solutions during the opening of productive deposits by drilling on the hydrodynamic perfection of the bottom borehole formation zone were carried out.

In drilling practice, when opening productive formations by drilling, they strive to minimize filtration into the formation by adjusting the "water output" parameter and intensifying the colmatation of the wall sections of the reservoir.

In the designs of the bottom hole with an "open" trunk, the hydrodynamic perfection of the well is largely determined by the contamination zone of the bottom-hole zone of the formation, since when this zone flows into the well, it creates additional hydrodynamic resistances, on which a significant part of the reservoir energy is spent on overcoming.

KEY WORDS: Bottom-hole formation zone, contamination of the productive formation, filtration crust, colmatation zone, filtrate penetration zone, permeability, filtration, skin factor.



агрязнение продуктивного пласта буровым раствором и его компонентами оказывает значительное влияние на снижение продуктивности нефтяных скважин. При бурении скважины в режиме репрессии на продуктивный пласт буровой раствор и его фильтрат проникают в глубь коллектора под действием 
этого перепада давления, изменяя фильтрационно-емкостные свойства призабойной зоны пласта.

В связи с этим проблема повышения качества первичного вскрытия продуктивных пластов с точки зрения увеличения их нефтегазоотдачи может быть решена только путем использования таких составов рабочих жидкостей, компоненты которых при проникновении в призабойной зоны пласта (ПЗП) в наименьшей степени снижали бы ее проницаемость для углеводородов в условиях конкретного объекта вскрытия. При этом состав и свойства этих жидкостей, а также режимные параметры технологических операций в скважине должны обеспечивать минимально возможные размеры зон их проникновения. С другой стороны, с целью сохранения коллекторских свойств продуктивных пластов рецептура буровых растворов для первичного вскрытия продуктивных горизонтов должна быть разработана на основе разрушающихся или растворимых агентов определенного гранулометрического состава, которые ограничивают фильтрацию в пласт и гарантированно могут быть из него удалены [1-15].

Чтобы оценить влияние кольматационного экрана (КЭ) на гидропроводность ПЗП на гранулярный коллектор с высокой проницаемостью, характерной для продуктивных отложений месторождений Южно-Тургайской впадины, рассмотрены следующие гипотетические ситуации в ПЗП.

1. Естественная проницаемость до вскрытия бурением составляла 2 мД (низкая толщина корки и зоны кольматации, но по проникновению фильтрата могут быть два варианта: $a$ - небольшая глубина, $\sigma$ - за счет капиллярной пропитки большая глубина проникновения фильтрата).

2. Естественная проницаемость до вскрытия бурением составляла 20 мД. (умеренная толщина корки и небольшая зона кольматации, глубина проникновения может быть высокой за счет продолжительности процесса вскрытия).

3. Естественная проницаемость до вскрытия бурением составляла 200 мД (толщина корки в пределах нормы, зона кольматации и проникновения фильтрата может регулироваться).

Используя формулу (1), можно оценить роль каждого из слоев системы, затрудняющих приток к скважине, результаты расчета приведены в таблице 1 [1].

$$
S_{3}=\ln \frac{r_{3}}{r_{\mathrm{c}}}[\beta-1]
$$

На основании расчетов зависимости скин-фактора от проницаемости показывается (рисунок 1), что влияние ФК на скин-фактор возрастает с увеличением проницаемости пород.

Удаление ФК с поверхности высокопроницаемого коллектора дает возможность существенно улучшить фильтрационные характеристики.

Усредненная проницаемость $\boldsymbol{k}^{*}$ зоны проникновения (ЗП), с учетом ее трехслойности (фильтрационная корка, слой с кольматирующей фазой и слой с фильтратом бурового раствора в ПЗП), определяется по формуле: 


\section{БУРЕНИЕ}

Таблица 1 - Результаты расчетов аналитических исследовании влияния зоны проникновения при вскрытии продуктивного пласта бурением на продуктивность скважин

\begin{tabular}{|c|c|c|c|c|c|c|c|c|c|c|c|}
\hline \multirow{2}{*}{ 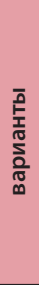 } & \multirow{2}{*}{ 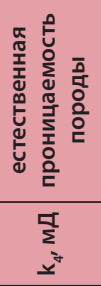 } & \multicolumn{2}{|c|}{$\begin{array}{c}\text { Фильтрационная } \\
\text { корка(ФК) }\end{array}$} & \multicolumn{2}{|c|}{$\begin{array}{c}\text { Зона } \\
\text { кольматации } \\
\text { (3К) }\end{array}$} & \multicolumn{2}{|c|}{$\begin{array}{c}\text { Зона } \\
\text { проникновения } \\
\text { фильтрата (ЗПФ) }\end{array}$} & \multicolumn{2}{|c|}{$\begin{array}{c}\text { Усредненная } \\
\text { проницаемость }\end{array}$} & \multicolumn{2}{|c|}{ Скин-эффект } \\
\hline & & $\begin{array}{l}\Sigma \\
=\end{array}$ & $\begin{array}{l}\underline{\sigma} \\
\Sigma \\
\Sigma\end{array}$ & $\sum_{\text {m }}$ & $\begin{array}{l}\sum^{\square} \\
\text { v }\end{array}$ & $\sum_{j}$ & $\begin{array}{l}\sum^{\mathrm{I}} \\
x^{m}\end{array}$ & 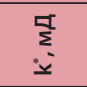 & 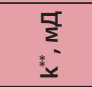 & in & in \\
\hline \multirow{4}{*}{1} & 2 & 0,188 & 0,01 & 0,205 & 0,5 & 0,505 & 1 & 0,468 & 0,928 & 3,2 & 1,1 \\
\hline & 2 & 0,186 & 0,1 & 0,205 & 0,5 & 0,705 & 1 & 0,833 & 0,945 & 1,9 & 1,4 \\
\hline & 2 & 0,186 & 0,1 & 0,34 & 0,5 & 0,84 & 1 & 0,661 & 0,719 & 3,1 & 2,6 \\
\hline & 2 & 0,186 & 0,1 & 0,205 & 0,5 & 1,205 & 1 & 0,875 & 0,960 & 2,4 & 2,0 \\
\hline \multirow{8}{*}{2} & 20 & 0,188 & 0,01 & 0,215 & 1 & 0,465 & 5 & 0,678 & 3,221 & 25,8 & 4,7 \\
\hline & 20 & 0,188 & 0,01 & 0,215 & 1 & 1,215 & 5 & 1,221 & 3,948 & 28,7 & 7,5 \\
\hline & 20 & 0,186 & 0,1 & 0,34 & 0,5 & 0,69 & 5 & 0,864 & 0,988 & 29,1 & 24,8 \\
\hline & 20 & 0,186 & 0,1 & 0,34 & 0,5 & 1,34 & 5 & 1,196 & 1,358 & 31,0 & 26,8 \\
\hline & 20 & 0,186 & 0,1 & 0,34 & 0,5 & 0,69 & 1 & 0,629 & 0,689 & 40,4 & 36,1 \\
\hline & 20 & 0,186 & 0,1 & 0,49 & 0,5 & 0,84 & 5 & 0,681 & 0,742 & 42,8 & 38,5 \\
\hline & 20 & 0,182 & 1 & 0,44 & 0,2 & 0,94 & 1 & 0,328 & 0,322 & 98,4 & 97,5 \\
\hline & 20 & 0,182 & 1 & 0,44 & 0,2 & 1,44 & 1 & 0,381 & 0,376 & 106,5 & 105,6 \\
\hline \multirow{12}{*}{3} & 200 & 0,188 & 0,01 & 0,215 & 5 & 0,465 & 50 & 0,824 & 22,291 & 218,8 & 7,1 \\
\hline & 200 & 0,188 & 0,01 & 0,215 & 5 & 0,715 & 50 & 1,207 & 27,182 & 220,1 & 8,4 \\
\hline & 200 & 0,188 & 0,01 & 0,215 & 5 & 0,465 & 25 & 0,813 & 16,104 & 221,9 & 10,2 \\
\hline & 200 & 0,188 & 0,01 & 0,29 & 5 & 0,54 & 50 & 0,913 & 10,768 & 230,0 & 18,3 \\
\hline & 200 & 0,186 & 0,1 & 0,34 & 5 & 0,74 & 50 & 4,006 & 10,305 & 67,6 & 25,0 \\
\hline & 200 & 0,186 & 0,1 & 0,34 & 5 & 1,14 & 50 & 5,131 & 12,745 & 68,9 & 26,3 \\
\hline & 200 & 0,186 & 0,1 & 0,34 & 5 & 0,74 & 25 & 3,833 & 9,218 & 70,7 & 28,1 \\
\hline & 200 & 0,186 & 0,1 & 0,49 & 5 & 0,89 & 50 & 3,780 & 7,667 & 81,3 & 38,7 \\
\hline & 200 & 0,182 & 1 & 0,44 & 25 & 1,94 & 100 & 25,879 & 47,978 & 15,9 & 7,3 \\
\hline & 200 & 0,182 & 1 & 0,44 & 25 & 3,44 & 100 & 30,248 & 53,480 & 16,5 & 7,9 \\
\hline & 200 & 0,182 & 1 & 0,44 & 25 & 1,94 & 50 & 22,266 & 36,726 & 18,9 & 10,3 \\
\hline & 200 & 0,182 & 1 & 0,44 & 12,5 & 1,94 & 100 & 18,926 & 28,329 & 22,6 & 14,0 \\
\hline
\end{tabular}

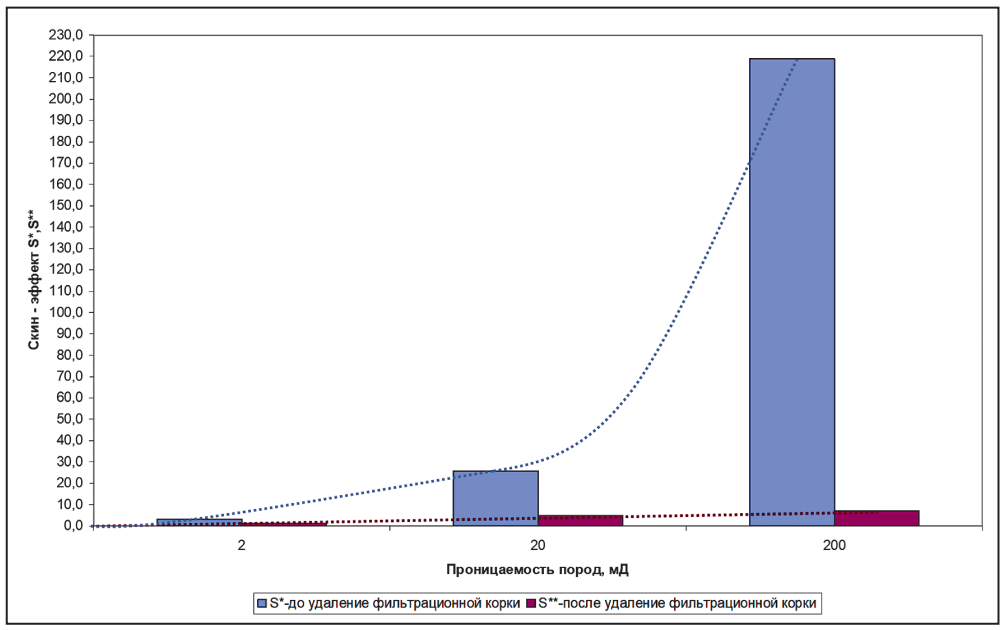

Рисунок 1 - Зависимость скин-фрактора от проницаемости коллектора (полулогарифмическая шкала) 


$$
k^{*}=\frac{\ln \frac{r_{4}}{r_{1}}}{\frac{\ln \frac{r_{2}}{r_{1}}}{k_{1}}+\frac{\ln \frac{r_{3}}{r_{2}}}{k_{2}}+\frac{\ln \frac{r_{4}}{r_{3}}}{k_{3}}} .
$$

Без фильтрационной корки усредненная проницаемость $\boldsymbol{k} * *$ ЗП определяется по формуле:

$$
k^{* * *}=\frac{\ln \frac{r_{4}}{r_{2}}}{\frac{\ln \frac{r_{3}}{r_{2}}}{k_{2}}+\frac{\ln \frac{r_{4}}{r_{3}}}{k_{3}}},
$$

где $\mathrm{r}_{1}$ - радиус скважины по корке; $\mathrm{k}_{1}$ - проницаемость корки; $\mathrm{r}_{2}$ - номинальный радиус скважины; $\mathrm{k}_{2}$ - проницаемость слоя кольматации; $\mathrm{r}_{3}-$ радиус участка кольматации; $\mathrm{k}_{3}-$ проницаемость слоя проникновении; $\mathrm{r}_{4}-$ радиус проникновения фильтрата.

Численные расчеты по формулам (2) и (3) при различных значениях $\beta, k$ и $r$ дают возможность сопоставить вклад каждого из участков ПЗП в общее загрязнение пласта при различных комбинациях исходной проницаемости пласта и параметров ФК, ЗК и ЗПФ. Расчеты $S \kappa$ и $S \kappa *$ показывают, что наибольшее влияние на «скин-фактор» для высокопроницаемых пород оказывает $\beta \Phi К$, которые имеют проницаемость по сравнению с породой на 2-3 порядка ниже (рисунок 2).

Степень влияния ФК, ЗК и ЗПФ на $S_{k}$ ПЗП зависит от исходной проницаемости коллектора. Для низкопроницаемого коллектора определяющим является влияние

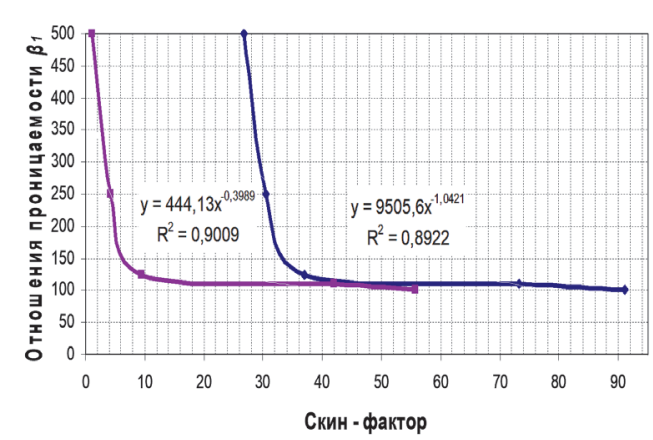

—до удаления фильтрацонной корки
—После удаления фильтрационной корк

A

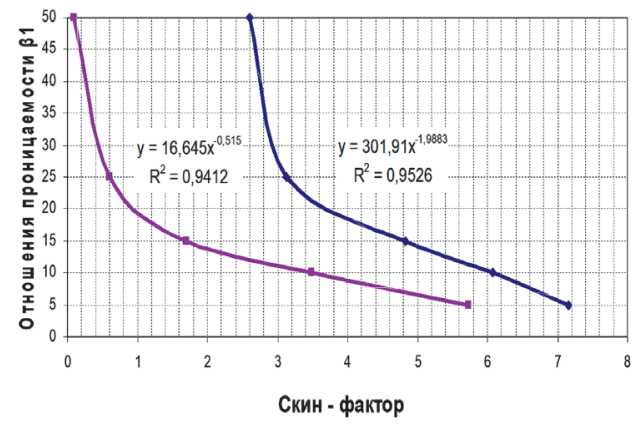

—до удаления фильтрационной корки
— после удаления фильтрационной корки

Б

Рисунок 2 - Влияние $\beta 1$ на скин-фрактор ПЗП «открытого» забоя скважины: $A$-для высокопроницаемых пород; 5 - для низкопроницаемых пород 
ФК и ЗПФ. Для высокопроницаемых коллекторов определяющим является влияние ФК и ЗК

В многочисленных публикациях свойства слоев зоны загрязнения пласта достаточно глубоко исследованы [1-15 и др.], что дает возможность сопоставить степень влияния каждого из них на гидродинамическое совершенство скважины. В качестве параметра, характеризующего гидродинамическое совершенство ПЗП, используем скин-фактор $S_{k}(1)[4,5,10]$.

Для оценки значимости каждого из слоев КЭ необходимо из общего скин-фактора ПЗС $S_{k}$, вычленить скин-фактор ЗП $S_{k}^{*}$, который с учетом многослойности зоны проникновения в ПЗС (1) имеет вид:

$$
S_{k}^{*}=\beta_{1} \ln \frac{r_{2}}{r_{1}}+\beta_{2} \ln \frac{r_{3}}{r_{2}}+\beta_{3} \ln \frac{r_{4}}{r_{3}}-\ln \frac{r_{4}}{r_{1}},
$$

где $\beta_{l}, \beta_{2}, \beta_{3}$ - соответственно $k_{4} / k_{l} ; k_{4} / k_{2} ; k_{4} / k_{3} ; k_{4}-$ исходная проницаемость ЗП.

Скин-фактор КЭ без фильтрационной корки $S_{k}^{* *}$ определяется по формуле:

$$
S_{k}^{* *}=\beta_{2} \ln \frac{r_{3}}{r_{2}}+\beta_{3} \ln \frac{r_{4}}{r_{3}}-\ln \frac{r_{4}}{r_{2}} .
$$

Анализ формул (4) и (5) дает возможность оценить зависимость параметров $S_{k}^{*}$ и $S_{k}^{* *}$ от каждого из слоев КЭ.

Наименьшей проницаемостью обладает ФК, которая в зависимости от свойств раствора и условий фильтрации на существенно ниже проницаемости коллектора и в большей степени зависит от свойств бурового раствора, чем от свойств коллектора $[4,5,10]$. Величина $\beta_{1}$ изменяется в диапазоне от нескольких десятков (для «рыхлых» корок) до сотен тысяч. Толщина фильтрационной корки изменяется в зависимости от свойств раствора и условий фильтрации от 0,002 м до 0,03 м, что соответствует значениям $\ln r_{2} / r_{1}$ от 0,01 до 0,17.

Наличие качественной ФК на стенках коллектора соответствует высокому значению $S_{k}^{*}$ (рисунок 3, таблица 2) и, как результат, существенному гидродинамическому барьеру на стенке ПЗП, а следовательно, высоким потерям давления при перемещении флюидов.

Для высокопроницаемых пород величина $S_{k}{ }^{*}$ может достигать значений нескольких сотен. Низкопроницаемая ФК является существенным барьером, препятствующим проникновению кольматирующей фазы и фильтрата бурового раствора в ЗП при вскрытии бурением (при оптимальном содержании коркообразующих фракций $[4,5,10]$. Так как при этом $\beta_{2}$ и $\beta_{3}$ существенно ниже $\beta_{1}$ и значения $\ln r_{3} / r_{2}$ и $\ln r_{4} / r_{3}$ не высокие, то удаление такой корки со стенки скважины $[11,13]$ в процессе вызова притока обеспечивает приемлемое значение скин-фактора зоны проникновения $S_{k}$ **.

Участок проникновения твердой фазы в ПЗП с заметным (от 2 до 40 раз) снижением природной проницаемости коллектора в зависимости от свойств раствора и условий фильтрации имеет протяженность до нескольких сантиметров. Произведение $\beta_{2} \cdot \ln r_{3} / r_{2}$ изменяется в диапазоне от долей единицы (при незначительной 


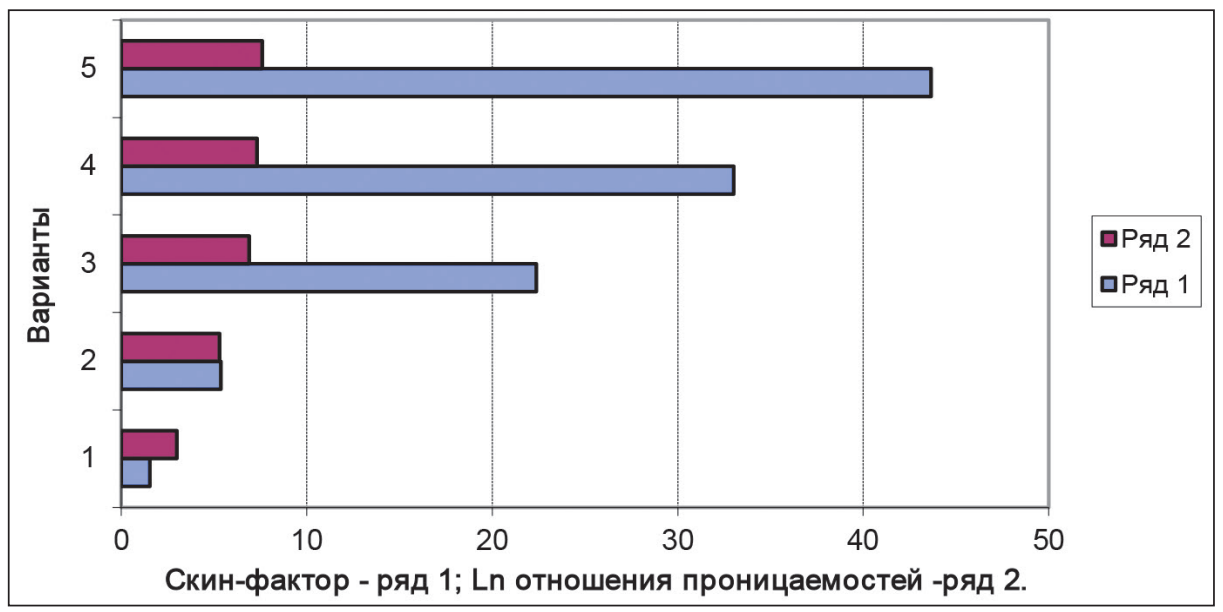

Рисунок 3 - Влияние отношения исходной проницаемости коллектора к проницаемости фильтрационной корки на скин-фрактор

Таблица 2 - Результаты расчета влияния фильтрационной корки на проницаемость и на скин фактор ПЗП при разных вариантах параметра пласта $\boldsymbol{r}_{1}-0,186 \mathrm{~m} ; \boldsymbol{r}_{2}-0,19 \mathrm{~m} ; \boldsymbol{\beta}_{2}-4: \boldsymbol{r}_{3}-0,205 \mathrm{~m} ; \boldsymbol{\beta}_{3}-2 ; \boldsymbol{r}_{4}-0,505 \mathrm{~m}$.

\begin{tabular}{|c|c|c|c|c|c|}
\hline варианты & $\boldsymbol{\beta}_{1}$ & $\boldsymbol{k}^{*}$, MKм $^{2}$ & $\boldsymbol{k}^{* *}{ }^{*} \mathrm{MKM}^{2}$ & $\boldsymbol{S}_{\boldsymbol{k}}{ }^{*}$ & $\boldsymbol{S}_{\boldsymbol{k}}{ }^{* *}$ \\
\hline 1 & 20 & 0,0008 & 0,0009 & 1,5 & 1,1 \\
\hline 2 & 200 & 0,0031 & 0,0093 & 5,4 & 1,1 \\
\hline 4 & 1000 & 0,0043 & 0,0464 & 22,4 & 1,1 \\
\hline 5 & 1500 & 0,0044 & 0,0696 & 33,0 & 1,1 \\
\hline
\end{tabular}

кольматации) до нескольких десятков (при принудительной кольматации). Наличие слоя кольматации (естественной или интенсифицированной за счет использования специальных технологий) увеличивает скин-фактор $S_{k} * *$.

Таким образом, исходная проницаемость ПЗП, по существу, определяет характер влияния слоев ПЗП на величину $S_{k}^{*}$ и $S_{k}^{* *}$ (значения $\beta_{1}, \beta_{2}, \beta_{3}$ в формулах (4) и (5)).

Для высокопроницаемой породы, для которой $\beta_{1}$ принимает значения десятки и сотни тысяч, отмечаются очень высокие значения $S_{k}^{*}$ при вскрытии бурением продуктивного пласта высококачественным буровым раствором, не смотря на незначительную толщину корки относительно других слоёв. Если эта корка имеет поверхностный характер без заметного проникновения кольматирующей фазы, то физическое (механическое, гидравлическое) или химическое (кислотные ванны, брейкеры и т.п. [7-9]) удаление фильтрационной корки может обеспечить приемлемые $S_{k}^{* *}$ при вызове притока (рисунок 3, варианты 4 и 5).

Для низкопроницаемых коллекторов $\left(\boldsymbol{k}_{4} \leq 0,001\right.$ мкм $\left.^{2}\right)$ проникновение кольматирующей фазы и фильтрата бурового раствора более заметно сказывается на величине $\boldsymbol{S}_{\boldsymbol{k}}{ }^{*}$ и требует значительных усилий для восстановления гидропроводности ЗП. 
Таким образом, стратегия формирования забоя с «открытым» стволом должна учитывать особенности слоистой структуры ПЗП и использовать технологические приёмы, либо щадящие коллектор (например, бурение на «равновесии»), либо обеспечивающие качественное восстановление гидропроводности ПЗП в процессе вызова притока.

Восстановление первоначальных гидродинамических характеристик коллектора в ПЗП может быть обеспечено эффективным разрушением фильтрационной корки и выносом продуктов реакции циркулирующим потоком раствора.

При высоких значениях $S_{k}^{* *}$ кроме удаления фильтрационной корки необходимо принимать меры по очистке ЗП (например, созданием массопереноса из пласта в скважину под действием гидродинамических, капиллярных и диффузионных градиентов давления [13-15]).

Очистке ПЗП (вытеснение твердой и жидкой фаз, проникших в ПЗП) при вызове притока благоприятствует наличие в буровом растворе твердой фазы с низкой адгезионной активностью (мел, сидерит, целестин и др.) и фильтратов скважинных жидкостей, разрыхляющих гидратные и сорбционные пленки на поверхности проницаемых каналов.

Выводы. Таким образом, при вскрытии продуктивного горизонта с проницаемостью коллектора 200 мд и более необходимо использовать буровой раствор, фильтрационные характеристики которого позволят создать на стенке ствола скважины непроницаемую и относительно небольшую по величине (до 1-2 мм) ФК. Это позволит минимизировать негативное влияние фильтрата и твердой фазы раствора на продуктивный пласт в процессе его вскрытия. Использование растворов, обладающих подобными фильтрационными свойствами, заметно увеличивает скин-эффект фильтрационной корки, препятствуя проникновению в пласт и тем самым заметно снижая протяженность зоны кольматации и проникновения, при этом практически не изменив исходной проницаемости коллектора.

При использовании бурового раствора указанного типа с заданными фильтрационными характеристиками необходимо учитывать необходимость удаления ФК, представляющей низкопроницаемый барьер на пути движения флюида в околоствольном пространстве скважины.

Для восстановления проницаемости ПЗП необходимо в процессе освоения скважины удалять ФК и вымывать из ЗК внедрившиеся фазы. Для упрощения очистки ПЗП необходимо для вскрытия продуктивных отложений использовать буровые растворы с дисперсной фазой, инертной по отношению к породе и пластовым флюидам, и с дисперсионной средой, имеющей низкую физико-химическую активность по отношению к пластовым флюидам и породе.

\section{ЛИТЕРАТУРА}

1 Сулейменов Н.С. Кандидатская диссертация «Разработка технологических и методических решений по формированию фильтрационных корок буровых растворов для последующего эфффективного разрушения при освоении скважины». - РГУ нефти и газа (НИУ) имени И. М. Губкина, 2020. [Sulejmenov N.S. Kandidatskaya dissertaciya «Razrabotka tekhnologicheskih i metodicheskih reshenij po formirovaniyu fil'tracionnyh korok burovyh rastvorov dlya posleduyushchego effektivnogo razrusheniya pri osvoenii skvazhiny». - RGU nefti i gaza (NIU) imeni I. M. Gubkina,2020]. 
2 Suleymenov N., Abilbek Zh., Erzhanova A., Akhmetov N., Tanzharikov P. Formation of filtration barriers in horizontal wells in the granulated reservoirs on the example of Aryskum field, scientific article // ARPN Journal of Engineering and Applied Sciences. - 2021. Vol. 16. - No. 17. - P. 1762-1766.

3 Сулейменов Н.С., Подгорнов В.М. Удаление фрильтрационных корок буровых растворов в процессе кислотной обработки с учетом фракционного состава карбонатного наполнителя // Вестник Ассоциации буровых подрядчиков. - 2019. - №4. - С. 8-11. [Sulejmenov N.S., Podgornov V.M. Udalenie fil'tracionnyh korok burovyh rastvorov $v$ processe kislotnoj obrabotki s uchetom frakcionnogo sostava karbonatnogo napolnitelya // Vestnik Associacii burovyh podryadchikov. - 2019. - №4. - S. 8-11.].

4 Михайлов Д.Н., Рыжиков Н.И., Шако В.В., Комплексный экспериментальный подход к определению кинетики кольматации пористых сред // Нефтяное хозяйство. - 2015. № 3. - C. 74-78[Mihajlov D.N., Ryzhikov N.I., SHako V.V., Kompleksnyj eksperimental'nyj podhod k opredeleniyu kinetiki kol'matacii poristyh sred // Neftyanoe hozyajstvo. - 2015. - № 3. - S.74-78.].

5 Макарова А.А. и др. Анализ чувствительности динамики очистки скважины и околоскважинной зоны к параметрам пласта, перфорации и свойствам бурового раствора // Нефтяное хозяйство. - 2015. - № 3. - С. 79-83[Makarova A.A. i dr. Analiz chuvstvitel'nosti dinamiki ochistki skvazhiny i okoloskvazhinnoj zony k parametram plasta, perforacii i svojstvam burovogo rastvora // Neftyanoe hozyajstvo. - 2015. - № 3. - S. 79-83].

6 Следков В.В., Леонов Е.Г. и др. Накопленная добыча нефти при средневзвешенной депрессии - основной показатель эффективного применения бурового раствора при вскрытии продуктивного пласта // Бурение и нефть. - 2015. - №10. - С. 26-32. [Sledkov V.V., Leonov E.G. i dr. Nakoplennaya dobycha nefti pri srednevzveshennoj depressii - osnovnoj pokazatel' effektivnogo primeneniya burovogo rastvora pri vskrytii produktivnogo plasta // Burenie i neft'. - 2015. - №10. - S. 26-32.].

7 Крылов В.И., Крецул В.В., Меденцев С.В. Современные технологические жидкости для заканчивания и капитального ремонта скважин // Строительство нефтяных и газовых скважин на суше и на море. - 2015. - № 1. - C. 36-44. [Krylov V.I., Krecul V.V., Medencev S.V. Sovremennye tekhnologicheskie zhidkosti dlya zakanchivaniya i kapital'nogo remonta skvazhin // Stroitel'stvo neftyanyh i gazovyh skvazhin na sushe i na more. - 2015. - № 1. - S. 36-44.].

8 Крылов В.И., Крецул В.В., Гимазетдинов В.М. Основные факторы, влияющие на загрязнение продуктивных пластов, и разработка рекомендаций по повышению продуктивности скважин // Строительство нефтяных и газовых скважин на суше и на море. - 2015. - № 12. - C. 31-36 [Krylov V.I., Krecul V.V., Gimazetdinov V.M. Osnovnye faktory, vliyayushchie na zagryaznenie produktivnyh plastov, i razrabotka rekomendacij po povysheniyu produktivnosti skvazhin // Stroitel'stvo neftyanyh i gazovyh skvazhin na sushe i na more. - 2015. - № 12. - S. 31-36].

9 Крылов В.И., Крецул В.В. Куксов В.А. Сверхтиксотропные промывочные жидкости нового поколения // Нефтяное Хозяйство. - 2004. - №11. - С. 56-58. [Krylov V.I., Krecul V.V. Kuksov V.A. Sverhtiksotropnye promyvochnye zhidkosti novogo pokoleniya // Neftyanoe Hozyajstvo. - 2004. - №11. - S. 56-58.].

10 Abrams, A.: «Mud Design to Minimize Rock Impairment Due to Particle Invasion,» JPT (May 1977). - P. 586.

11 Акимов Н.И., Стрижнев К.В., Чернов А.В., Павлов И.В. Влияние параметров пласта на продуктивность горизонтальных скважин // Интервал. - 2006. - №4. - С. 38-43[Akimov 
N.I., Strizhnev K.V., CHernov A.V., Pavlov I.V. Vliyanie parametrov plasta na produktivnost' gorizontal'nyh skvazhin // Interval. - 2006. - №4. - S. 38-43].

12 Крылов В.И., Крецул В.В. Новый подход к методам химической очистки призабойной зоны ствола скважины при заканчивании открытым стволом // Бурение и нефть. 2005. - №10. - C. 21-23.[Krylov V.I., Krecul V.V. Novyj podhod k metodam himicheskoj ochistki prizabojnoj zony stvola skvazhiny pri zakanchivanii otkrytym stvolom // Burenie i neft'. - 2005. - №10. - S. 21-23].

13 Подгорнов В.М. Заканчивание скважин. - М.: РГУ нефти и газа им. Губкина, 2017. C. 14-47. [Podgornov V.M. Zakanchivanie skvazhin. - M.: RGU nefti i gaza im. Gubkina, 2017. - S. 14-47].

14 Подгорнов В.М., Сулейменов Н.С. Моделирования загрязнения при первичном вскрытии пласта бурением и очистки путем установки кислотной ванны. - Алматы: Вестник КБТУ, 2008. - С. 29-34. [Podgornov V.M., Sulejmenov N.S. Modelirovaniya zagryazneniya pri pervichnom vskrytii plasta bureniem i ochistki putem ustanovki kislotnoj vanny. - Almaty: Vestnik KBTU, 2008. - S. 29-34.].

15 Подгорнов В.М. Формирование приза бойной зоны скважины. - М.: РГУ нефти и газа им. И.М. Губкина, 2005. - С. 5-29.[Podgornov V.M. Formirovanie prizabojnoj zony skvazhiny. - M.: RGU nefti i gaza im. I.M. Gubkina, 2005. - S. 5-29.]. 